УДК 539.219 .3

\title{
Структура слоев диффузной зоны при борировании стали 20
}

\author{
Е.П. Шевчук', В.А. Плотников ${ }^{2}$, А.Б. Садибеков ${ }^{3}$ \\ ${ }^{1}$ Восточно-Казахстанский государственный университет им. С. Аманжолова \\ (Усть-Каменогорск, Казахстан) \\ ${ }^{2}$ Алтайский государственный университет (Барнаул, Россия) \\ ${ }^{3}$ Восточно-Казахстанский государственный технический университет \\ им. Д. Серикбаева (Усть-Каменогорск, Казахстан)
}

\section{The Structure of Diffuse Zone Layers When Boriding Steel 20}

\author{
E.P. Shevchuk', V.A. Plotnikov ${ }^{2}$, A.B. Sadibekov ${ }^{3}$ \\ ${ }^{1}$ Sarsen Amanzholov East Kazakhstan State University (Ust-Kamenogorsk, Kazakhstan) \\ ${ }^{2}$ Altai State University (Barnaul, Russia) \\ ${ }^{3}$ D. Serikbayev East Kazakhstan State Technical University (Ust-Kamenogorsk, \\ Kazakhstan)
}

\begin{abstract}
Представлены данные об изменении структуры поверхностных слоев стали 20 путем борирования при высоких температурах с применением химикотермической обработки. По данным исследований тонкой структуры и микродифракционного фазового анализа образцов, основными фазами полученных в экспериментах боридных слоев являются соединения железа с бором $\mathrm{FeB}, \mathrm{Fe}_{2} \mathrm{~B}$ и В. Микроструктура исследуемых образцов окрашена: фаза FeB окрашивается в коричневый цвет, а $\mathrm{Fe}_{2} \mathrm{~B}$ сохраняет желтые тона, кристаллы бора окрашены в белый цвет. В приповерхностном слое наблюдались поры размером около 50 мкм. Исследование количественных характеристик боридных структур помогло определить среднюю толщину диффузных слоев образцов и коэффициент диффузии в них.

Для предотвращения спекания порошков железа и борной кислоты в насыщающую смесь введена инертная добавка - $\mathrm{Na}_{2} \mathrm{SiO}_{3}$, а для ускорения процесса борирования - активаторы $\left(\mathrm{NH}_{4} \mathrm{OH}, \mathrm{C}\right)$. Выяснено, что с уменьшением содержания инертной добавки в насыщающей смеси толщина диффузионного боридного слоя снижается и также уменьшается размер боридных игл.

Ключевые слова: борирование, микроструктура, бориды, инертная добавка, активаторы, боридные иглы, диффузия, коэффициент диффузии.
\end{abstract}

DOI 10.14258/izvasu(2019)4-08
The paper presents data on changes in the structure of surface steel 20 by boriding at high temperatures using chemical-thermal treatment. According to studies of fine structure and microdiffraction phase analysis of samples, the main phases obtained in the experiments of boride layers are iron compounds with boron $\mathrm{FeB}, \mathrm{Fe}_{2} \mathrm{~B}$ and $\mathrm{B}$. The microstructure of the samples is colored: the FeB phase is colored brown, and $\mathrm{Fe}_{2} \mathrm{~B}$ retains yellow tones, boron crystals are colored in white color. Pores measuring about 50 microns in size are observed in the surface layer. The study of the quantitative characteristics of the boride structures helps determine the average thickness of the diffuse layers of the samples and determine the diffusion coefficient in them.

To prevent sintering of iron and boric acid powders, an inert additive, $\mathrm{Na}_{2} \mathrm{SiO}_{3}$, is introduced into the saturating mixture, and activators $\left(\mathrm{NH}_{4} \mathrm{OH}, \mathrm{C}\right)$ are used to accelerate the boriding process. It is found out that with the decrease of the content of the inert additive in the saturating mixture, the thickness of the diffusion boride layer decreases, and the size of boride needles also decreases.

Key words: boriding, microstructure, borides, inert additive, activators, boride needles, diffusion, diffusion coefficient. 


\section{Введение}

Как показывают результаты многих исследований, боридные слои являются одними из наиболее износостойких диффузионных слоев [1-5]. Однако такие слои на основе боридов обладают достаточно высокой хрупкостью. Снижения хрупкости можно достичь путем структурной модификации борированных слоев [6].

Высокая хрупкость боридов железа, наличие микротрещин и пор в боридном слое - основная причина разрушения поверхностного слоя. Боридные частицы, отделившиеся от поверхностного слоя, способствуют развитию абразивного изнашивания $[7,8]$.

Снизить хрупкость боридного слоя можно путем формирования композиционной структуры этого слоя. Пластичность композиционных структур во много раз выше, чем пластичность сплошного боридного слоя, следовательно, и абразивное изнашивание будет значительно меньше [7].

Таким образом, появляется целесообразность перевода компактной структуры боридного слоя в композиционную структуру борированного слоя либо на всей поверхности, подвергающейся физическим воздействиям, либо в отдельных ее зонах. В этой связи целью данной работы является изменение структуры поверхностных слоев стали 20 путем борирования при высоких температурах с применением химикотермической обработки. Насыщение поверхностного слоя происходит при нагреве детали до определенной температуры в среде, легко выделяющей насыщающий элемент в активном состоянии, и выдержке при этой температуре [8].

\section{Методика и материалы}

Химико-термическую обработку стальных образцов осуществляли в индукционной печи. На образцы цилиндрической формы из стали 20 на торцевую поверхность наносили обмазку, содержащую смесь железного порошка и борной кислоты в стехиометрическом соотношении $\mathrm{Fe}-25 \%+\mathrm{H}_{3} \mathrm{BO}_{3}-75 \%$, в качестве инертной добавки введен $\mathrm{Na}_{2} \mathrm{SiO}_{3}$, а для ускорения процесса борирования - активаторы $\left(\mathrm{NH}_{4} \mathrm{OH}, \mathrm{C}\right)$. Борирование проводили при $1000^{\circ} \mathrm{C}$ в течение 5 мин. Представлены результаты исследований трех образцов, в обмазке которых варьировали содержание инертной добавки, причем в образце 3 инертная добавка отсутствовала.

Исследования тонкой структуры и микродифракционный фазовый анализ образцов проводились на просвечивающем электронном микроскопе JEOLJSM-6390LV с рентгеновским микроанализатором в режиме вторичных и обратно рассеянных электронов, а также на растровом электронном микроскопе Quanta 3D 200i. Условия измерения в приборе были следующими: ускоряющее напряжение 20 кВ, размер зонда на образце 1-2 мкм². Для исследования особенностей структуры поверхности образцов на рас- тровом электронном микроскопе их предварительно полировали и травили электрохимическим методом и только затем проводили съемку рельефа поверхности образцов и микроанализ участков матрицы и частиц вторичных фаз.

Для изучения общего характера микроструктуры использовали оптический микроскоп NEOPHOT-21. Электрохимическую полировку и травление образцов проводили в соответствии с рекомендациями, приведенными в работах $[9,10]$.

\section{Экспериментальные результаты}

Основными фазами полученных в экспериментах боридных слоев являются соединения железа с бором $\mathrm{FeB}, \mathrm{Fe}_{2} \mathrm{~B}$ и В. Эти фазы в образцах 1, 2, 3 сформировали композиты с твердостью 3395, 2837, 2862 МПа соответственно. Как правило, боридные слои имеют игольчатое строение, сформированное фазами ромбического борида $\mathrm{FeB}$ и тетрагонального борида $\mathrm{Fe}_{2} \mathrm{~B}$. Однако структура слоев, характер распределения фаз в слое и распределение твердости во многом зависят от технологии получения - способа борирования и условий насыщения (температуры и времени) [11].

Исследование микроструктуры борированных образцов показало, что слои состоят по крайней мере из двух фаз боридов и матрицы Ст20 (рис. 1). Характерно, что микроструктура исследуемых образцов окрашена: фаза FeB окрашивается в коричневый цвет, a $\mathrm{Fe}_{2} \mathrm{~B}$ сохраняет желтые тона, кристаллы бора окрашены в белый цвет.

В нашем случае при температуре около $1000{ }^{\circ} \mathrm{C}$ на поверхности образца формируется пористая зона столбчатых боридных кристаллов, к которой примыкает зона крупных равноосных кристаллов боридов.

Высокобористая фаза (FeB) располагается отдельными включениями на поверхности. Это хорошо видно по степени травления (рис. 1б). Кроме этого, в приповерхностном слое наблюдались поры размером около 50 мкм (рис. 1а и 16). В образце 3 (рис. 1в) поры отсутствуют.

Появление пористой структуры поверхности связано с быстрой истощаемостью насыщающей смеси. Казалось бы, что такая структура неприемлема. Однако пористая структура боридного слоя является наиболее оптимальной в условиях трения с использованием смазочного материала, так как полученная открытая пористость играет роль маслоудерживающих резервуаров.

Результаты борирования углеродистых сталей зависят от содержания углерода в сталях. Исследование влияния углерода на глубину борированного слоя показало, что изменение содержания углерода от 0,06 до 0,45 \% сопровождается достаточно интенсивным снижением глубины борированного слоя [12].

Весь процесс насыщения можно разбить на 3 стадии $[13$, с. $65-70]$ : 


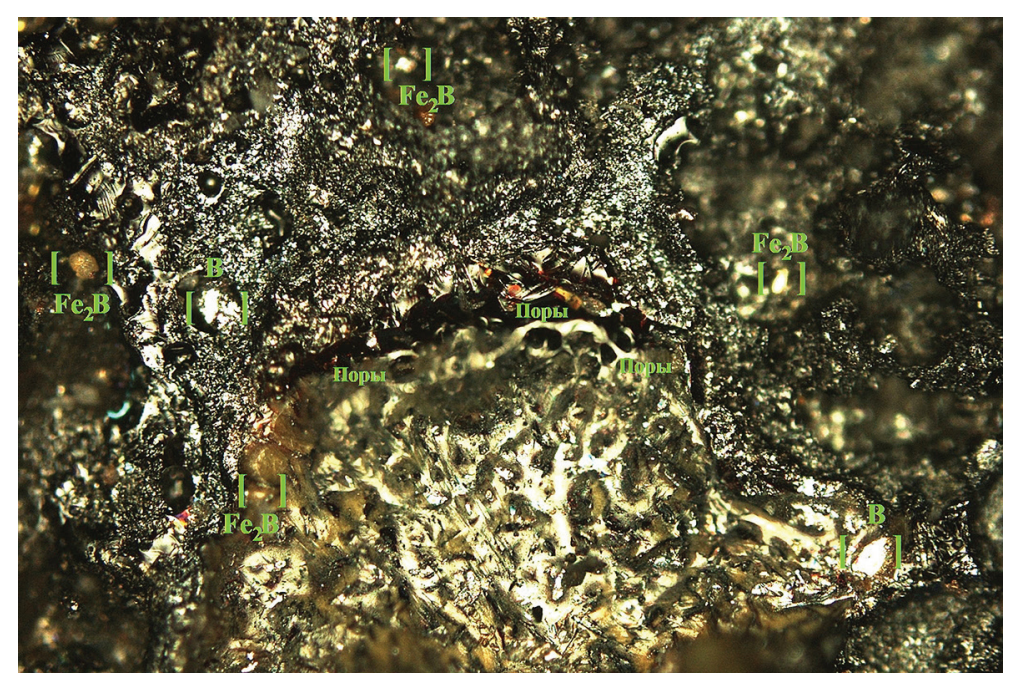

a

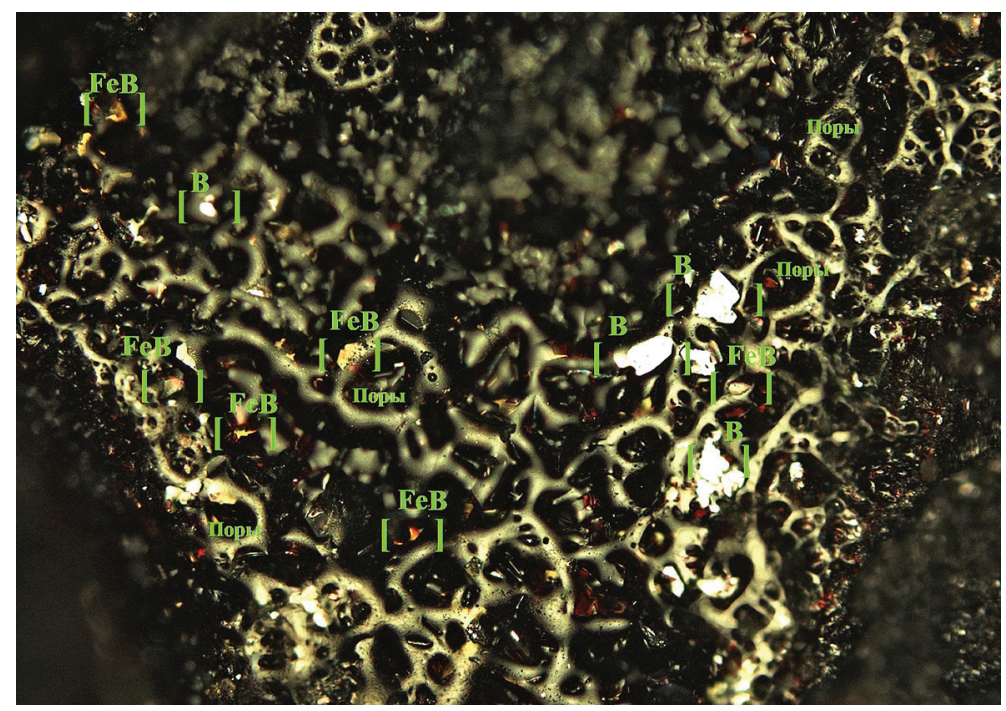

6



Рис. 1. Бориды в поверхностных слоях стали 20 образцов, увеличение х100: a $-1,6-2$, в -3 
1 стадия (от 0 до 0,05 ч) - процесс адсорбции, совмещенный с атомарной диффузией по межзеренным границам;

2 стадия (от 0,05 до 0,15 ч) - процесс диффузии, совмещенный с образованием слоя боридов;
3 стадия - установившийся процесс диффузии через слой боридов с последующим ростом слоя боридов за счет «реакционной диффузии».

Растровая электронная микроскопия позволяет исследовать количественные характеристики боридных структур (рис. 2).
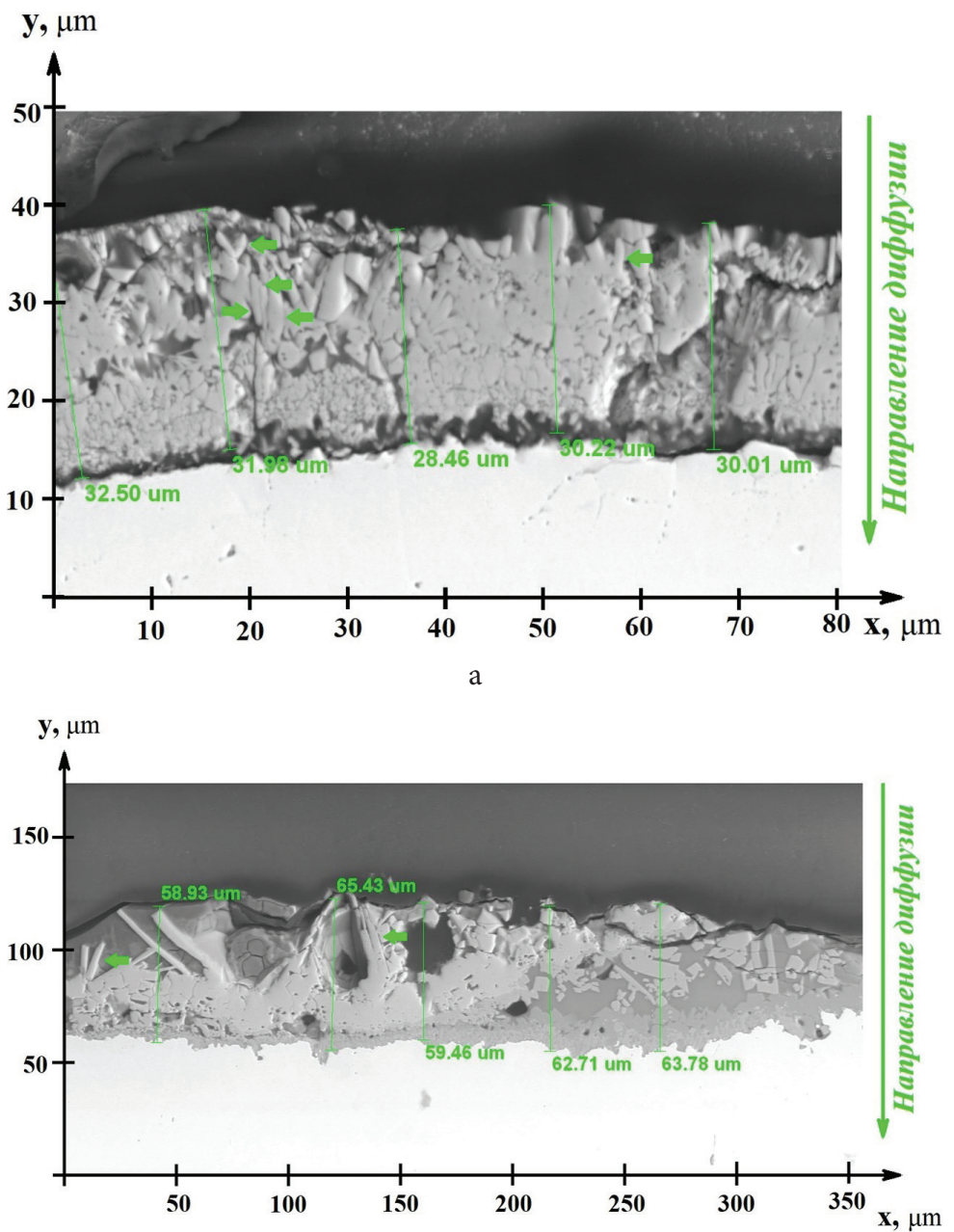

6

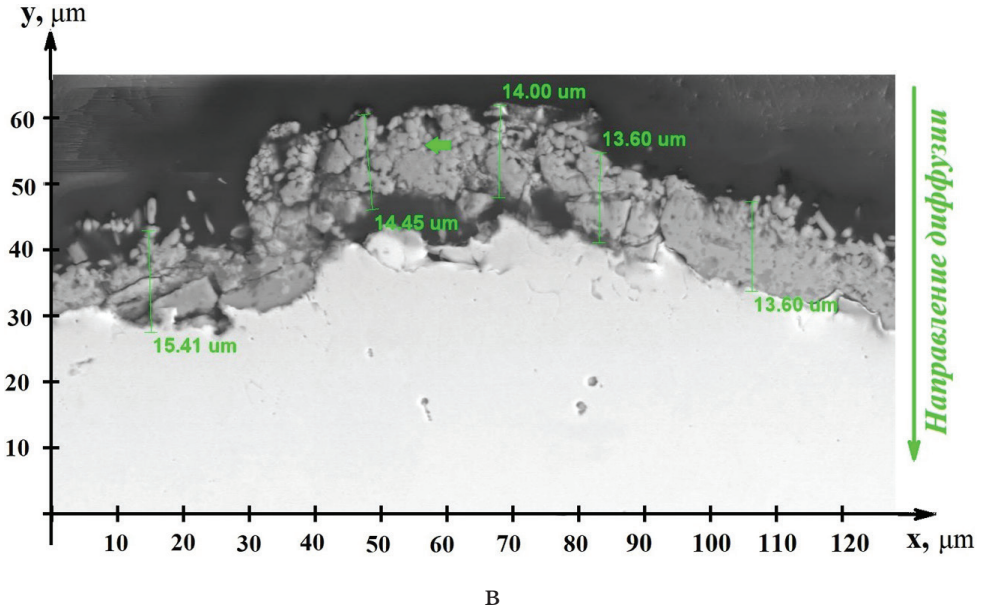

Рис. 2. Растровая электронная микроскопия диффузионных слоев после борирования: а - образец 1; 6 - образец 2; в - образец 3 
На рис. 2а видно, что средняя величина толщины диффузионного слоя в образце 1 составляет 30,6 мкм (на рисунках зеленым цветом обозначена толщина диффузионного слоя, зелеными стрелками - зерна). Наблюдается хорошо выраженная игольчатая структура кристаллов $\mathrm{Fe}_{2} \mathrm{~B}$, направленных нормально поверхности образца. Согласно рис. 2a, ориентация кристаллов определена по их положениям в предполагаемой системе координат. Так, величина зерен по оси Y составляет от 4,3 мкм до 6,43 мкм, а по оси $\mathrm{X}$ - от 0,023 мкм до 1,8 мкм.

В образце 2 (рис. 26) также хорошо различается игольчатая структура кристаллов F В. В этом образце средняя толщина диффузионного слоя около 62,18 мкм. На площади исследования в 3333,2 кв. мкм выявлено 120 зерен, 112 из них в диффузионном слое расположены перпендикулярно слою подложки. Размер зерна по оси Ү составляет от 0,08 до 2,16 мкм, по оси $\mathrm{X}$ - от 0,08 мкм до 0,58 мкм.

Микроструктура диффузионного слоя образца 3 (рис. 2в) представлена вкраплениями бора в железной матрице в виде белых точек. Толщина диффузного слоя в этом случае самая маленькая из исследуемых в данной работе - 14,45 мкм. Размер зерен также невелик и составляет: по оси Ү от 0,160 мкм до 3,21 мкм, по оси $\mathrm{X}$ - от 0,16 мкм до 1,6 мкм.

Для предотвращения спекания порошков железа и борной кислоты в насыщающую смесь в качестве инертной добавки введен $\mathrm{Na}_{2} \mathrm{SiO}_{3}$, а для ускорения процесса борирования - активаторы ( $\left.\mathrm{NH}_{4} \mathrm{OH}, \mathrm{C}\right)$. С уменьшением содержания инертной добавки в насыщающей смеси (в образце 3 ее нет совсем) толщина диффузионного боридного слоя снижается. Как видно из рисунка 2, толщина слоя боридов снижается в 4 раза и уменьшается размер боридных игл в 2 раза, т.е. наблюдается увеличение дисперс- ности слоя. Одновременно с ростом дисперсности боридного слоя усложняется его строение - боридные иглы становятся закругленными, наблюдается их рост не только по нормали к поверхности, но и под некоторым углом, толщина боридных игл также увеличивается.

В процессах борирования массопереноса бора к фронту реакции контролируется диффузией с учетом того, что весь поступающий бор расходуется на реакции, т.е. накопления свободного бора в насыщающем материале не происходит [8]. Известно, что коэффициент диффузии бора в боридах железа при температуре $950{ }^{\circ} \mathrm{C}$ составляет $1,82 \cdot 10^{-11} \mathrm{M}^{2} / \mathrm{c}$, а в переходной зоне $-1,53 \cdot 10^{-10} \mathrm{M}^{2} / \mathrm{c}$ [14].

Вычисленные коэффициенты диффузии в образцах 1, 2, 3 в соответствии с методикой, изложенной в публикациях $[15,16]$, составили значения $1,56 \cdot 10^{-12} \mathrm{M}^{2} / \mathrm{c}, 6,44 \cdot 10^{-12} \mathrm{M}^{2} / \mathrm{c}, 0,35 \cdot 10^{-12} \mathrm{M}^{2} /$ с соответственно. Очевидно, низкие значения коэффициентов диффузии в нашем случае обусловлены медленным течением процесса борирования в углеродистых сталях по сравнению с этим же процессом в чистом железе [8].

\section{Заключение}

Проведенные исследования боридного слоя в стали 20 показали, что состав борирующей смеси существенно влияет на структуру боридных покрытий, а следовательно, и на их свойства. Наличие инертной составляющей $\mathrm{Na}_{2} \mathrm{SiO}_{3}$ приводит к формированию пористой структуры борированного слоя, а уменьшение концентрации инертной компоненты снижает толщину боридного слоя почти в три раза и приводит к исчезновению пор. Изменение концентрации инертной компоненты влияет и на соотношение фаз в боридных слоях. В боридном слое образца 3 присутствует лишь борид $\mathrm{Fe}_{2} \mathrm{~B}$, в то время как в образцах 1 и 2 наблюдается смесь боридных фаз $\mathrm{FeB}$ и $\mathrm{Fe}_{2} \mathrm{~B}$.

\section{Библиографический список}

1. Sizova O.V., Kolubaev A.V. Einflu $\beta$ der Struktur von Borid-Schutzschichten auf Reibung und Gleitverschlei $\beta$ // Tribolodie-Fachtagung 1996, Reibung, Schweirung und Verschleiß, 1996. Göttingen, 1996. Vort. 27/1.

2. Колубаев А.В., Тарасов С.Ю., Трусова Г.В., Сизова О.В. Структура и свойства однофазных боридных покрытий // Изв. вузов. Черная металлургия. 1994. № 7.

3. Колубаев А.В., Трусова Г.В., Тарасов С.Ю., Сизова О.В. Особенности структуры и триботехнические свойства боридных покрытий // Матер. Междун. симпозиума Триболог-10M-Slavyantribo-1. Рыбинск ; М., 1993.

4. Зобнев В.В., Марков А.М., Иванов С.Г., Гурьев А.М. Износостойкость многокомпонентных диффузионных боридных покрытий на рабочих органах сельскохозяйствен- ных машин // Актуальные проблемы в машиностроении. 2014. № 1.

5. Баландин Ю.А. Износостойкие комплексные покрытия на основе бора // Защита металлов. 2006. Т. 42. № 2.

6. Быкова Т.М. Влияние химического состава стали на структуру и свойства диффузионных боридных покрытий : дисс. ... канд. технич. наук. Екатеринбург, 2016.

7. Сизов И.Г. Оценка хрупкости боридных слоев после электронно-лучевого борирования // Современные наукоемкие технологии. 2005. № 11.

8. Гурьев А.М., Лыгденов Б.Д., Гурьев М.А., Мэй Шунчи, Власова О.А. Борирование малоуглеродистой стали // Междунар. журнал экспериментального образования. 2015. № 12 (4). 
9. Волков П. А. Особенности приготовления объектов для просвечивающей электронной микроскопии из аморфных алюминиевых сплавов // Кристаллография. 2011. T. 56. № 3.

10. Кринов Д. И., Ефимов А. В. Особенности подготовки препаратов и методы травления рудных минералов // Уральский минералогический сборник. 2008. № 15.

11. Миркин Л.И. Справочник по рентгеноструктурному анализу поликристаллов. М., 1961.

12. Гурьев А. М. Высокоэффективный способ химикотермической обработки инструментальных сталей // Ползуновский альманах. 2004. № 4.
13. Иванова Т.Г. Изучение диффузии бора в углеродистых и легированных сталях : дисс. ... канд. физ.-мат. наук. Барнаул, 2015.

14. Пачурин В.Г., Галкин В.В., Пачурин Г.В. Оценка деформационной неоднородности в раскатанных изделиях с клиновым профилем // Фундаментальные исследования. 2014. № 11 (4).

15. Мерер Х. Диффузия в твердых телах : монография / пер. с англ. Долгопрудный, 2011.

16. Балгазин И.И., Саяпова В.В. Нахождение коэффициента диффузии методом Монте-Карло // Universum: Химия и биология : электрон. научн. журн. 2018. № 5 (47). 